\title{
The Amino Acid Sequence of Dromedary Pancreatic Ribonuclease
}

\author{
By GJALT W. WELLING, GERDA GROEN and JAAP J. BEINTEMA \\ Biochemisch Laboratorium, Zernikelaan, Rijksuniversiteit, \\ Groningen, The Netherlands
}

(Received 13 November 1974)

\begin{abstract}
Dromedary (Camelus dromedarius) RNAase (ribonuclease) was isolated from pancreatic tissue by affinity chromatography. Peptides obtained by digestion with different proteolytic enzymes and $\mathrm{CNBr}$ were isolated by gel filtration, preparative high-voltage paper electrophoresis and paper chromatography. Peptides were sequenced by the dansylEdman method. All peptide bonds were overlapped by one or more peptides. The polypeptide chain consists of 123 amino acids. A deletion (position 39) was observed in an external loop of the polypeptide chain (residues 35-40), as was found earlier in horse RNAase (Scheffer \& Beintema, 1974). A heterogeneity was found at position 103 (glutamine and lysine). Dromedary RNAase differs at $23-32 \%$ of the positions from all other pancreatic RNAases sequenced to date. In evolutionary terms this indicates that dromedary RNAase has evolved independently during the larger part of the evolution of the mammals. Detailed evidence for the sequence has been deposited as Supplementary Publication SUP 50046 (14 pages) at the British Library (Lending Division), Boston Spa, Wetherby, W. Yorks. LS23 7BQ, U.K., from whom copies may be obtained on the terms given in Biochem. J. (1975) 145, 5.
\end{abstract}

The comparative study of pancreatic RNAase* structure was started by Anfinsen et al. (1959). With semiquantitative data obtained by digestion of oxidized sheep RNAase with trypsin and chymotrypsin, the primary structure was compared with that of bovine RNAase (Smyth et al., 1963). Since then, primary structures of RNAases from rat (Beintema \& Gruber, 1973), pig(Jackson \& Hirs, 1970; Wierenga et al., 1973), red deer, roe deer (Zwiers et al., 1973), sheep (Kobayashi \& Hirs, 1973), goat (Welling et al., 1974b), giraffe (Gaastra et al., 1974), horse (Scheffer \& Beintema, 1974), reindeer (Leijenaar-van den Berg et al., 1974), European elk, fallow deer (G. Leijenaarvan den Berg \& J. J. Beintema, unpublished work), chinchilla, guinea pig (A and B component), coypu (van den Berg \& Beintema, 1975) and muskrat (H. van Dijk, B. Sloots, A. van den Berg, W. Gaastra \& J. J. Beintema, unpublished work) have been determined. Their comparative study may yield valuable information on structure-function relationships in the protein RNAase and on the phylogeny of pancreatic RNAases.

Here we present the primary structure of dromedary (Camelus dromedarius) pancreatic RNAase.

\section{Experimental \\ Materials}

Pancreatic tissue was kindly given by Dr. B. A. Peleg, Bet Dagan (Israel).

* Abbreviation: RNAase, ribonuclease; Aet, aminoethyl.
Enzymes. Trypsin (pig, three times crystallized; batch UK 6) was from Miles-Seravac (Maidenhead, Berks., U.K.). Thermolysin was from Calbiochem (San Diego, Calif., U.S.A.) (three times crystallized; A grade; lot 100939) or from Chugai Boyaki Co., (Osaka, Japan). Carboxypeptidases A and B (treated with di-isopropyl phosphorofluoridate) and pepsin (two times crystallized) were products from Worthington Biochemical Corp. (Freehold, N.J., U.S.A.). Aminopeptidase $M$ was from Röhm and Haas (Darmstadt, Germany). Chymotrypsin was obtained from Boehringer (Mannheim, Germany). Subtilisin Carlsberg was a gift from Novo Industri (Copenhagen, Denmark), from whom subtilisin Novo was also obtained. Staphylococcus aureus V8 proteinase was a gift from Dr. G. Drapeau (University of Montreal, Montreal, Que., Canada).

Materials for chromatography and electrophoresis. Sephadex G-25 and G-50 were products of Pharmacia (Uppsala, Sweden). Whatman 3MM chromatography paper was from W. and R. Balston (Maidstone, Kent, U.K.). Polyamide layers were from Carl Schleicher and Schüll (Dassel, Germany). Ionex-25 SA $\left(\mathrm{Na}^{+}\right)$ layers were obtained from Macherey, Nagel and Co. (Düren, Germany).

Reagents. Analytical-grade reagents were used if available. Fluorescamine was from Hoffmann-La Roche (Basel, Switzerland). Ethyleneimine, $\mathrm{CNBr}$ and dansyl chloride were from Fluka A.G. (Buchs, Switzerland). $\beta$-Mercaptoethanol, ethyl acetate and phenylisothiocyanate were 'sequanal-grade' products from Pierce Chemical Co. (Rockford, Ill., U.S.A.). 
Trifluoroacetic acid was 'sequanal-grade' from Pierce or from Merck A.G. (Darmstadt, Germany). It was twice-distilled before use. Silica-gel thin layers with fluorescence indicator were from M. Woelm (Eschwege, Germany). Phenanthrenequinone was from Schuchardt (München, Germany).

\section{Methods}

Isolation. Dromedary RNAase was isolated from the combined pancreatic tissue of six animals by affinity chromatography as described by Wierenga et al. (1973) by acetone precipitation. Carbohydrate was detected by the orcinol- $\mathrm{H}_{2} \mathrm{SO}_{4}$ method (Winzler, 1955).

Electrophoresis in polyacrylamide gels was performed with $10 \%$ gels in $0.35 \mathrm{M}-\beta$-alanine acetate buffer, pH4.5. Gels were stained in $0.5 \%$ Amido Black in $7 \%(\mathrm{v} / \mathrm{v})$ acetic acid, followed by destaining in $7 \%$ acetic acid. Duplicate gels were incubated with yeast RNA (BDH, Poole, Dorset, U.K.) and stained with $0.2 \%$ Toluidine Blue as described by Wilson (1969).

Amino acid analysis. Amino acid analyses were performed with a Beckman 120-C or Technicon TSM-1 amino acid analyser. Samples were hydrolysed in $0.4 \mathrm{ml}$ of $6 \mathrm{M}-\mathrm{HCl}$ at about $110^{\circ} \mathrm{C}$ in evacuated [13.3 Pa $(0.1 \mathrm{mmHg})]$ sealed glass tubes for $18-96 \mathrm{~h}$. For peptides usually $18-20 \mathrm{~h}$ was used. The amounts of cysteic acid, homoserine, homoserine lactone and aminoethylcysteine were not determined. The recovery of aminoethylcysteine was often low.

Hydrolysis with carboxypeptidases $A$ and $B$ and with aminopeptidase $M$. Dromedary RNAase $(0.7 \mathrm{mg})$ in $0.2 \mathrm{M}-\mathrm{N}$-ethylmorpholine acetate buffer, $\mathrm{pH} 6.5$, containing $0.1 \%$ sodium dodecyl sulphate was incubated at $37^{\circ} \mathrm{C}$ with $0.05 \mathrm{mg}(1 \mu \mathrm{l})$ of carboxypeptidase A suspension for $4 \mathrm{~h}$. Free amino acids were detected with the TSM-1 amino acid analyser.

Aminopeptidase $\mathbf{M}$ digestion of peptides was carried out in $0.2 \mathrm{M}-N$-ethylmorpholine acetate buffer, $\mathrm{pH} 8.0$, at $37^{\circ} \mathrm{C}$.

Digestion of peptides with a mixture of carboxypeptidases A and B was performed as described by Sajgó \& Dévényi (1972). The amino acids generated by carboxypeptidase and aminopeptidase digestion were analysed on Ionex-25 SA layers (Dévényi et al., 1971).

Cleavage methods and peptide nomenclature. Dromedary RNAase $(40 \mathrm{mg})$ was aminoethylated and digested with trypsin as described by Zwiers et al. (1973). The numbers of the fragments obtained from this digest are prefixed by the letter $T$. Dromedary RNAase $(20 \mathrm{mg})$ was oxidized with performic acid at $0^{\circ} \mathrm{C}$ (Hirs, 1956) and digested with thermolysin as described by Ambler \& Meadway (1968). The numbers of the fragments obtained from this digest are prefixed by the letter $\mathbf{H}$. After gel filtration of the thermolysin digest, any uncleaved material and any large peptides that there might have been were digested with subtilisin Novo (Ambler, 1963). The fragment obtained from this digest is denoted by the letters HS. Dromedary RNAase $(20 \mathrm{mg})$ was cleaved with $\mathrm{CNBr}$ in $70 \%$ (v/v) formic acid (Schroeder et al., 1969). The numbers of the fragments obtained from this digest are prefixed by the letters $\mathrm{CN}$. After gel filtration the void-volume peak was oxidized with performic acid. Subsequent gel filtration provided a void-volume peak which was digested with a proteinase from Staphylococcus aureus V8 (Glu-enzyme) as described by Houmard \& Drapeau (1972). The numbers of the fragments obtained from this digest are prefixed by the letter $\mathrm{G}$. The smaller peptides were isolated by gel filtration and the larger peptides were digested with trypsin (Ambler, 1963). The numbers of the fragments obtained from this digest are also prefixed by the letter $G$. Dromedary RNAase $(20 \mathrm{mg})$ was digested with pepsin (Ambler, 1963). The larger peptides were incubated with $0.2 \mathrm{mg}$ of chymotrypsin in $0.2 \mathrm{M}-N$-ethylmorpholine acetate, $\mathrm{pH} 8.0$, for $4 \mathrm{~h}$ at $37^{\circ} \mathrm{C}$. The numbers of the fragments obtained from this digest are prefixed by the letters PC. About $100 \mathrm{nmol}$ of peptide CN3 was cleaved with $0.01 \mathrm{mg}$ of chymotrypsin in $0.2 \mathrm{M}-N$-ethylmorpholine acetate, $\mathrm{pH} 8.0$, for $3 \mathrm{~h}$ at $37^{\circ} \mathrm{C}$. The fragment obtained from this digest is denoted CN3Ch. Dromedary RNAase $(4 \mathrm{mg})$ was digested with subtilisin Carlsberg (Welling et al., 1974a). The fragment obtained from this digest is denoted by the letter $S$.

Peptides have been numbered according to their position in the polypeptide chain.

Gel filtration of peptides. After cleavage of dromedary RNAase the first purification step was gel filtration on Sephadex G-25 or G-50. Generally peptides were fractionated on a column $(0.8 \mathrm{~cm} \times 190 \mathrm{~cm})$ of Sephadex G-25 (superfine-grade) with $0.1 \mathrm{M}$-acetic acid at a flow rate of $7 \mathrm{ml} / \mathrm{h}, 1.5 \mathrm{ml}$ fractions being collected.

The thermolysin and pepsin digests were fractionated on a column $(1 \mathrm{~cm} \times 100 \mathrm{~cm})$ of Sephadex G-25 (fine grade) with $5 \%$ formic acid and $0.1 \mathrm{M}-\mathrm{NH}_{3}$ respectively, at a flow rate of $20 \mathrm{ml} / \mathrm{h}, 1 \mathrm{ml}$ fractions being collected. The S-peptide was isolated by gel filtration on a column $(1 \mathrm{~cm} \times 100 \mathrm{~cm})$ of Sephadex G-50 (superfine-grade) with $0.05 \mathrm{M}-\mathrm{HCl}$ at a flow rate of $15 \mathrm{ml} / \mathrm{h}, 1.5 \mathrm{ml}$ fractions being collected.

Determination of peptide positions in column eluates. The eluates of the column fractionations were monitored for $E_{280}$ by using an LKB Uvicord II instrument or by measuring either the $E_{280}$ or $E_{220}$, or both, in a Zeiss PMQ II spectrophotometer. Peptide 'maps' were obtained by subjecting a suitable portion of each fraction appearing after the void volume to high-voltage paper electrophoresis at 
pH6.5 (Ambler, 1963) or at pH3.5 (Wierenga et al., 1973).

Preparative high-voltage paper electrophoresis was performed at pH6.5 and 3.5 (Ambler, 1963). For additional purification, paper chromatography in butan-1-ol-acetic acid-water-pyridine (BAWP) (15:3:10:12, by vol.) (Waley \& Watson, 1953) or high-voltage paper electrophoresis at $\mathrm{pH} 4.8$ (Welling et al., 1974b) was used.

Detection of peptides on paper. Guide strips of the preparative electrophoresis were stained with $0.2 \%$ ninhydrin in acetone or with $50 \mu \mathrm{g}$ of fluorescamine/ $\mathrm{ml}$ of acetone mixed with an equal volume of $1 \%$ pyridine in acetone. Specific stains for arginine (Yamada \& Itano, 1966), tyrosine (Jepson \& Smith, 1953) and histidine (Dent, 1947) were also used.

Elution. Purified peptides were eluted from paper strips into small tubes with $0.1 \mathrm{M}-\mathrm{NH}_{3}$ and dried.

Dansylation. Dansylation was carried out as described by Gros \& Labouesse (1969) by using $0.05 \mathrm{M}-\mathrm{NaHCO}_{3}, \quad \mathrm{pH} 10.0$, (with $0.1 \mathrm{M}-\mathrm{NaOH}$ ). Identification of dansyl-amino acids was achieved by t.l.c. on polyamide sheets $(5 \mathrm{~cm} \times 5 \mathrm{~cm})$ (Woods \& Wang, 1967) by using a standard mixture of dansylamino acids (Hartley, 1970).

Sequence determination. Dansyl-Edman degradation was carried out by the method of Gray (1972) for extended degradations.

Automatic Edman degradation was carried out in a JEOL sequence analyser by using a doublecleavage programme. Phenylthiohydantoin derivatives of amino acids were identified by t.l.c. on silica gel with fluorescence indicator in xylene-propan-2-ol $(7: 2, \mathrm{v} / \mathrm{v})$ (Inagami \& Murakami, 1972). The spots were located at $254 \mathrm{~nm}$ and stained with ninhydrincollidine in ethanol (Roseau \& Pantel, 1969).

Amide positions. Amide positions were assigned by using digestion with aminopeptidase and carboxypeptidase, or the method of Offord (1966), or evidence from automated Edman degradation (phenylthiohydantoin derivatives of amino acids). Additional information was provided by the specificity of the staphylococcal proteinase (Glu-enzyme).

\section{Results}

From $550 \mathrm{~g}$ of pancreatic tissue $240 \mathrm{mg}$ of dromedary RNAase was isolated. The elution pattern of the affinity chromatography was comparable with that of giraffe RNAase (Gaastra et al., 1974). With the orcinol- $\mathrm{H}_{2} \mathrm{SO}_{4}$ method no carbohydrate could be demonstrated (Winzler, 1955). On polyacrylamidegel electrophoresis only one enzymically active band was visible.

Determination of the $\mathrm{N}$-terminal residue by the dansylation method yielded only serine. Automatic Edman degradation of dromedary RNAase showed the $N$-terminal sequence to be: Ser-Glu-Thr-Ala-Ala-
Glu-Lys-Phe-X-Arg-Gln-X-Met-X-X-Tyr (X= unknown). Incubation with carboxypeptidase A showed Ser-Val to be the $C$-terminal sequence. The amino acid analyses and the composition derived from the sequence of dromedary RNAase are shown in Table 1 of Supplementary Publication SUP 50046. The observed agreement between the analyses and the composition is quite satisfactory. Half-cystine was not determined. The sequence determination, however, showed cysteine at positions exactly corresponding to those in the other pancreatic RNAases.

\section{Isolation of peptides}

Generally, peptide mixtures resulting from the different digests were fractionated on columns of Sephadex G-25 (see Fig. 1 of the supplement). Subsequent paper electrophoresis was used to decide how to pool fractions for further purification (see Fig. 2 of the supplement).

With the $\mathrm{CNBr}$ cleavage we used a different approach. After $\mathrm{CNBr}$ cleavage the resulting mixture was fractionated on a Sephadex G-25 (superfinegrade) column (Fig. 3 of the supplement). The voidvolume peak was subjected to performic acid oxidation and applied to the same column (Fig. 4 of the supplement). The void-volume peak, probably containing about three-quarters of the molecule, was treated with the Glu-enzyme. The resulting peptide mixture was fractionated on the same Sephadex column as mentioned above (Fig. 5 of the supplement).

The smaller peptides of these fractionations were purified by paper electrophoresis at $\mathrm{pH}$ 3.5. The three peaks of the final gel filtration that contained the larger peptides were separately digested with trypsin, fractionated on the Sephadex column and purified by paper electrophoresis at $\mathrm{pH} 3.5$. In some cases paper electrophoresis at a different $\mathrm{pH}$ or paper chromatography, or both, was necessary to purify the peptides.

\section{Sequence determination}

The amino acid analyses of the isolated peptides are given in Tables 2, 3, 4 and 5 of Supplementary Publication SUP 50046. Peptides that have been subjected to dansyl-Edman degradation to give the complete amino acid sequence are shown in Table 6 of the supplement. Peptides needed for overlap are given in Table 7 of the supplement. The remaining pepttdes from Tables 2-5 of the supplement were used for amide assignments and complementary sequence evidence. The evidence for the amide assignment is shown in Table 8 of the supplement. The results of the sequence determination are summarized in Fig. 1.

\section{Specificity of the proteolytic enzymes and $\mathrm{CNBr}$}

One site of chymotrypsin-like cleavage by pig trypsin was observed: that between tyrosine-16 and serine-17. Thermolysin cleaved in agreement with its 


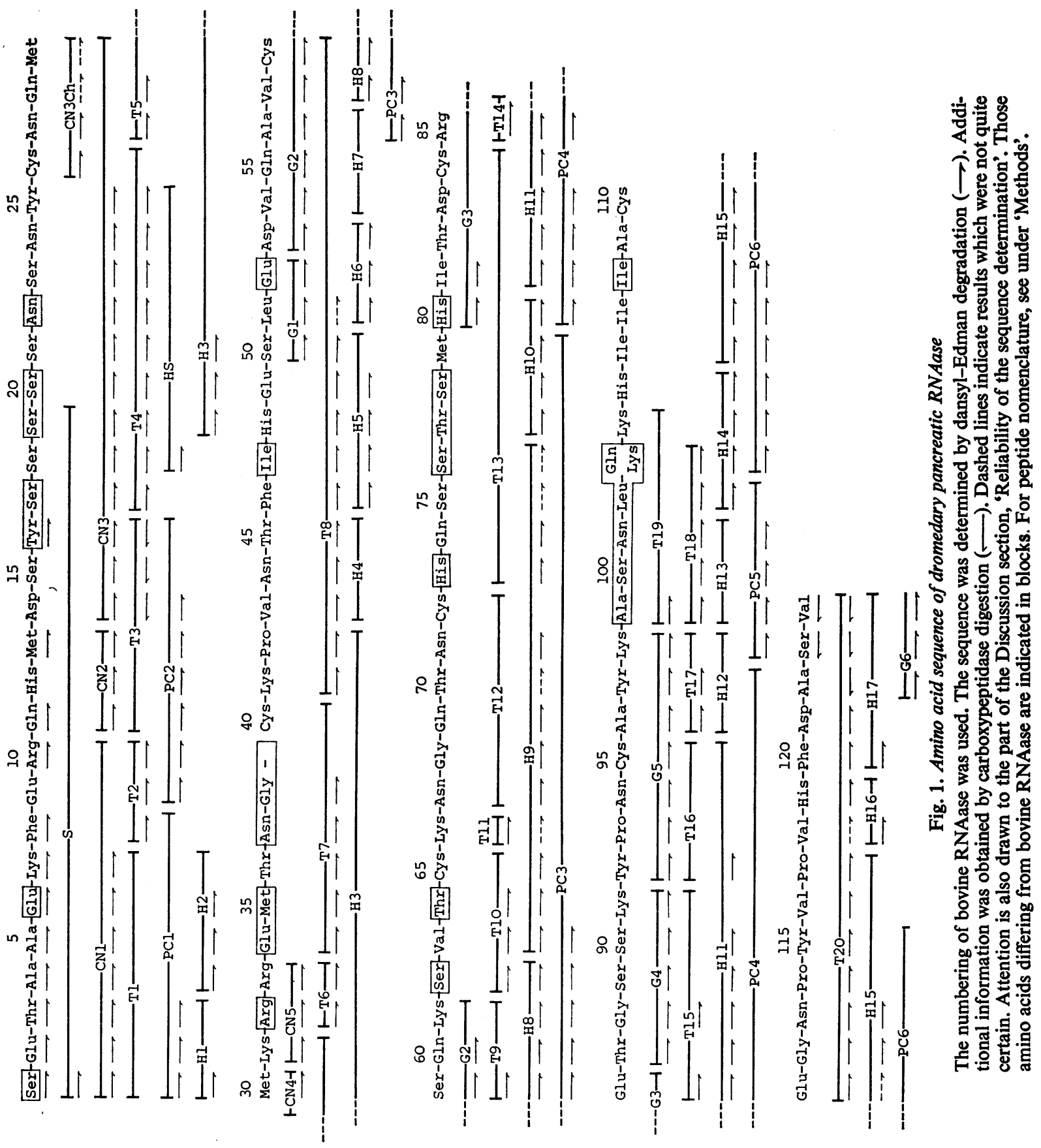


known specificity (Ambler \& Meadway, 1968) except for a -Ser-Ser- (18-19) cleavage. Pepsin digestion of dromedary RNAase yielded a few small impure peptides. The larger peptides have been cleaved with chymotrypsin. No unusual cleavage was found with chymotrypsin. $\mathrm{CNBr}$ treatment of dromedary RNAase yielded some surprising 'tryptic' cleavages: at -Arg-Gln- (10-11) and -Arg-Glu- (33-34). The staphylococcal proteinase showed cleaving behaviour next to glutamic acid residues (Houmard \& Drapeau, 1972). Cleavage was also encountered next to one aspartic acid residue (121) in the $C$-terminal sequence His-Phe-Asp-Ala-Ser-Val. Comparable behaviour was observed towards the $C$-terminal part of lesser rorqual RNAase, His-Phe-Asp-Asn-Ser-Val (M. Emmens, G. W. Welling \& J. J. Beintema, unpublished work) and in kangaroo RNAase, His-PheAsp-Ala-Tyr-Val (B. van Dijk, G. W. Welling, W. Gaastra \& J. J. Beintema, unpublished work).

\section{Supplementary information}

Detailed evidence for the amino acid sequence of dromedary RNAase has been deposited with the National Lending Library for Science and Technology, Boston Spa, Wetherby, W. Yorks. LS23 7BQ, U.K. (Supplementary Publication SUP 50046). The information comprises: (1) amino acid composition of dromedary RNAase; (2) Tables showing the compositions of all peptides used for assembly of the amino acid sequence; (3) a Table showing the peptides used for assembly of the amino acid sequence and which residues have been sequenced; (4) a Table showing the overlapping peptides used for assembly of the amino acid sequence; (5) Tables which give the evidence for the presence or absence of amide groups on each aspartic acid or glutamic acid residue; (6) Figures showing the elution pattern of the gel filtration of the thermolysin digest and the elution patterns of successive gel-filtration steps after $\mathrm{CNBr}$ treatment, digestion with the Glu-enzyme and digestion with trypsin; (7) a Figure showing the analysis by paper electrophoresis at pH6.5 of the thermolysin digest.

\section{Discussion}

\section{Reliability of the sequence determination}

The peptide bonds of the $N$-terminal part of dromedary RNAase (residues 1-25) have been overlapped three to five times by relatively pure peptides. Most residues have been found as their dansyl derivative more than once. In contrast with this, we could hardly establish the sequence of residues 67-79. Peptide bonds were overlapped only once by relatively impure peptides. Dansyl-Edman results were also more difficult to interpret because we had to use peptides with amino acid analyses which were not always satisfactory.

In Tables 2-5 of Supplementary Publication SUP 50046 a distinction has been made between very pure peptides, peptides with small impurities and rather impure peptides. In Table 6 of the supplement the peptides used for the amino acid sequence are shown. Six peptides have been used containing small impurities. These impurities, however, did not interfere with the dansyl-Edman technique.

The amino acid composition of the impure peptide H3 (residue 19-42) contains more lysine residues than suggested by the sequence. Compared with the other pancreatic RNAases sequenced to date, a lysine residue could be inserted between residues 33 and 34 or residues 40 and 41 . However, because the recovery of free lysine in the tryptic digest was rather low and could be accounted for by the lysine residues at position 66 and position 104, we think this insertion to be less probable.

To obtain an overlap we also used the rather impure peptide T13 (Table 3 of Supplementary Publication SUP 50046). Obviously this is a peptide mixture, but it apparently connects the sequence His-Gln-Ser-SerThr-Ser-Met (73-79) with His-Ile-Thr-Asp-Cys (8084). Additional evidence for this rather difficult part of the sequence was provided by the large peptide PC3, which connects the sequence 56-72 with 73-79. Peptides T5 (residues 27-31; Asn-Gln-Met-Met-Lys) and T10 (residues 62-65; Ser-Val-Thr-Aet-Cys) were isolated as a mixture in relative amounts of 42 and $58 \%$ respectively. They showed the same mobility on paper electrophoresis and after paper chromatography. However, in the latter case, the relative amounts were changed in favour of peptide T10 (see Table 3 of the supplement), probably because of oxidation of the two methionine residues in peptide T5. This mixture was sequenced by the dansylEdman technique, during which peptide T5 only interfered with the Edman degradation by giving a weak spot of dansyl-glutamic acid after one step. From the amino acid composition of the mixture and the sequence results, the composition of peptide T5 could be deduced. One peptide, $\mathrm{CN} 3$, showed a rather peculiar amino acid composition: Asp (4), Ser (7), Glu (1), Tyr (2) and Hse (+). The sequence determination proved to be fairly easy, because the peptide contained the invariant residue tyrosine-25. After 11 Edman steps had been carried out on peptide CN3, dansylation of the remaining peptide showed bisDns-Tyr. The sequence was supported by the dansylEdman degradation of tryptic peptide T4, which partially overlaps $\mathrm{CN} 3$ and contains tyrosine-25. 


\section{Table 1. Difference matrix of pancreatic RNAases}

Data were derived from publications mentioned in the introduction. A deletion was treated as an amino acid. Compared with horse and rat RNAase, the relative differences were calculated on the basis of 126 and 127 amino acid residues respectively. Latin names for the species investigated are as follows: cow (Bos taurus), sheep (Ovis aries), goat (Capra hircus), giraffe (Giraffa camelopardalis), reindeer (Rangifer tarandus), dromedary (Camelus dromedarius), pig (Sus scrofa), horse (Equus caballus) and rat (Rattus rattus).

$\begin{array}{lcccccccc} & \text { Cow } & \text { Sheep/goat } & \text { Giraffe } & \text { Reindeer } & \text { Dromedary } & \text { Pig } & \text { Horse } & \text { Rat } \\ \text { Cow } & & 3 \% & 9 \% & 11 \% & 23 \% & 21 \% & 28 \% & 35 \% \\ \text { Sheep/goat } & 4 & & 6 \% & 8 \% & 23 \% & 19 \% & 25 \% & 33 \% \\ \text { Giraffe } & 11 & 7 & & 11 \% & 27 \% & 23 \% & 27 \% & 38 \% \\ \text { Reindeer } & 14 & 10 & 14 & & 26 \% & 20 \% & 26 \% & 35 \% \\ \text { Dromedary } & 28 & 28 & 33 & 32 & & 23 \% & 26 \% & 32 \% \\ \text { Pig } & 26 & 23 & 28 & 25 & 281 & & 24 \% & 36 \% \\ \text { Horse } & 35 & 31 & 34 & 33 & 33 & 30 & & 35 \% \\ \text { Rat } & 44 & 42 & 48 & 45 & 41 & 46 & 45 & \end{array}$

\section{Heterogeneity}

One unmistakable heterogeneity (Lys, Gln) was found at position 103. Several peptides in this region have been isolated.

$\begin{array}{lc}\text { T18 } & \text { Ala-Ser-Asn-Leu-Lys } \\ \text { T19 } & \text { Ala-Ser-Asn-Leu-Gln-Lys } \\ \text { H14 } & \text { Leu-Gln-Lys-His } \\ \text { PC6 } & \text { Lys-Lys-His-Ile-.. }\end{array}$

The thermolysin peptide $\mathrm{H} 14$ showed a mobility of 0.80 relative to lysine at $\mathrm{pH} 6.5$. This could explain why the very basic thermolysin peptide Leu-Lys-LysHis was lost (see Fig. 2 of the supplement). Whether this heterogeneity in dromedary RNAase reflects polymorphism in the population or the existence of two different structural genes needs to be investigated on individual pancreatic tissue. Despite the fact that the heterogeneity involves a difference in charge, only one band was observed on gel electrophoresis. This would suggest that there should be another heterogeneity elsewhere in the protein, which compensates for the difference at position 103. No such heterogeneity has been found, however.

Camel RNAase (Camelus bactrianus) was isolated from one pancreas. A sample was aminoethylated and digested with trypsin. In this case only glutamine was observed at position 103.

\section{Comparison of sequences}

In Table 1 a difference matrix of pancreatic RNAases is shown. One oustanding feature that can be deduced from this matrix is that dromedary RNAase differs to the extent of between 23 and $32 \%$ of its residues from all other pancreatic RNAases sequences thus far. This suggests that dromedary RNAase has evolved independently during the larger part of the evolution of the mammals. This agrees with the classical taxonomy (Romer, 1962), in which the dromedary is an early offshoot in the phylogenetic tree of the artiodactyls.

Another interesting point is that dromedary RNAase exhibits a deletion at position 39 compared with all other pancreatic RNAases sequenced to date, except for horse RNAase which has the same deletion (Scheffer \& Beintema, 1974).

\section{Comparison with the tertiary structure of bovine RNAase}

To compare the amino acid sequence of dromedary RNAase with the three-dimensional structure of bovine RNAase, we used a model of RNAase-S (Wyckoff et al., 1970). Some 28 differences with the bovine enzyme were observed. Of the substitutions $80 \%$ were found clustered in three parts of the molecule: residues 62,64 and 73 ; a large cluster with residues $16,17,19,20,22,76,77,80,99,100,101$, 102 and 103; and a loop (34-39) with substitutions of residues 34, 35, 37, 38 and 39 (Fig. 2).

Seven of the replacements involve hydrophobic residues, of which two are completely internal: Val (47) $\rightarrow$ Ile and Val (108) $\rightarrow$ Ile. The side chains of the two isoleucine residues can easily be fitted in the largest of three internal cavities termed cavity B by Lee \& Richards (1971) without altering the polypeptide backbone.

Introduction of the other substitutions also did not bring about alterations in the polypeptide chain of any significance, except for the deletion at position 39. This replacement introduces a radical change in the polypeptide backbone. It shortens an external loop in the structure of the molecule. In having this deletion, dromedary RNAase differs from all other RNAases except for the horse enzyme, in which the same important mutation has occurred in parallel. The loop in the RNAases of these two species differs only at position 37 (asparagine in the dromedary and 


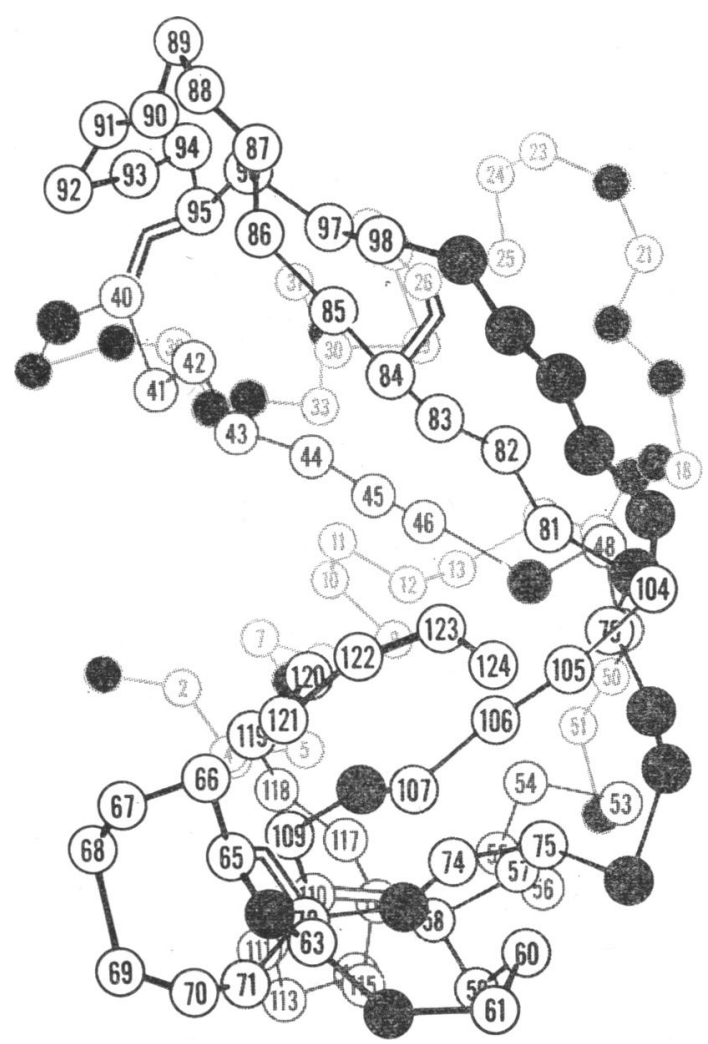

Fig. 2. Structure of RNAase A

Substitutions in dromedary RNAase are shown in black. (From R. E. Dickerson \& I. Geis, The Structure and Action of Proteins, W. A. Benjamin Co., Menlo Park, Calif. Copyright 1969 by Dickerson and Geis.)

glutamine in the horse enzyme). For this reason, the computer-drawn stereo picture of the hypothetical structure of this loop in horse RNAase (Scheffer \& Beintema, 1974) will also be valid for dromedary RNAase.

We thank Dr. B. A. Peleg, Kimron Veterinary Institute, Bet Dagan (Israel) for the dromedary pancreatic tissue. The hospitality of Dr. R. P. Ambler, Department of Molecular Biology, Edinburgh, to G. W. W. is greatly acknowledged. We thank Dr. G. Drapeau for a sample of the staphylococcal proteinase. Part of this work was carried out under the auspices of the Netherlands Foundation for Chemical Research (S.O.N.) and with financial aid from the Netherlands Organisation for the Advancement of Pure Research (Z.W.O.).

\section{References}

Ambler, R. P. (1963) Biochem. J. 89, 349-378

Ambler, R. P. \& Meadway, R. J. (1968) Biochem. J. 108, 893-895

Anfinsen, C. B., Åqvist, S. E. G., Cooke, J. P. \& Jönsson, B. (1959) J. Biol. Chem. 234, 1118-1123

Beintema, J. J. \& Gruber, M. (1973) Biochim. Biophys. Acta 310, 161-173

Dent, C. E. (1947) Biochem. J. 41, 240-253

Dévényi, T., Hazai, I., Ferenczi, S. \& Báti, J. (1971) Acta Biochim. Biophys. Acad. Sci. Hung. 6, 385-388

Gaastra, W., Groen, G., Welling, G. W. \& Beintema, J. J. (1974) FEBS Lett. 41, 227-233

Gray, W. R. (1972) Methods Enzymol. 25b, 333-344

Gros, C. \& Labouesse, B. (1969) Eur. J. Biochem. 7, 463470

Hartley, B. S. (1970) Biochem. J. 119, 805-822

Hirs, C. H. W. (1956) J. Biol. Chem. 219, 611-621

Houmard, J. \& Drapeau, G. R. (1972) Proc. Natl. Acad. Sci. U.S.A. 69, 3506-3509

Inagami, T. \& Murakami, K. (1972) Anal. Biochem. 47, 501-504

Jackson, R. L. \& Hirs, C. H. W. (1970) J. Biol. Chem. 245, 637-653

Jepson, J. B. \& Smith, I. (1953) Nature (London) 172, 1100 1101

Kobayashi, R. \& Hirs, C. H. W. (1973) J. Biol. Chem. 248, 7833-7837

Lee, B. \& Richards, F. M. (1971) J. Mol. Biol. 55, 379-400

Leijenaar-vanden Berg, G., Migchelsen, C. \& Beintema, J. J. (1974) FEBS Lett. 48, 218-221

Offord, R. E. (1966) Nature (London) 211, 591-593

Romer, A. S. (1962) The vertebrate body, 3rd edn., p. 6779, Saunders, Philadelphia

Roseau, G. \& Pantel, P. (1969) J. Chromatogr. 44, 392-395

Sajgó, M. \& Dévényi, T. (1972) Acta Biochim. Biophys. Acad. Sci. Hung. 7, 233-236

Scheffer, A. J. \& Beintema, J. J. (1974) Eur. J. Biochem. 46, 221-233

Schroeder, W. A., Shelton, J. B. \& Shelton, J. R. (1969) Arch. Biochem. Biophys. 130, 551-556

Smyth, D. G., Stein, W. H. \& Moore, S. (1963) J. Biol. Chem. 238, 227-234

van den Berg, A. \& Beintema, J. J. (1975) Nature (London) 253, 207-210

Waley, S. G. \& Watson, J. (1953) Biochem. J. 57, 529-538

Welling, G. W., Groen, G., Gabel, D., Gaastra, W. \& Beintema, J. J. (1974a) FEBS Lett. 40, 134-138

Welling, G. W., Scheffer, A. J. \& Beintema, J. J. (1974b) FEBS Lett. 41, 58-61

Wierenga, R. K., Huizinga, J. D., Gaastra, W., Welling, G. W. \& Beintema, J. J. (1973) FEBS Lett. 31, 181-185

Wilson, C. W. (1969) Anal. Biochem. 31, 506-611

Winzler, R. J. (1955) Methods Biochem. Anal. 2, 279-311

Woods, K. R. \& Wang, K. T. (1967) Biochim. Biophys. Acta 133, 369-370

Wyckoff, H. W., Tsernoglou, D., Hanson, A. W., Knox, J. R., Lee, B. \& Richards, F. M. (1970) J. Biol. Chem. 245, 305-328

Yamada, S. \& Itano, H. A. (1966) Biochim. Biophys. Acta 130, 538-540

Zwiers, H., Scheffer, A. J. \& Beintema, J. J. (1973) Eur. J. Biochem. 36, 569-574 